\title{
Induction of Glutamate Binding Sites in Hippocampal Membranes by Transient Exposure to High Concentrations of Glutamate or Glutamate Analogs
}

\author{
Markus Kessler, Michel Baudry, Joseph T. Cummins, “ Susan Way, and Gary Lynch \\ Center for the Neurobiology of Learning and Memory and Department of Psychobiology, University of California, \\ Irvine, California 92717, and *Addiction Research Laboratory, V. A. Hospital, Sepulveda, California 91343
}

\begin{abstract}
The number of $\mathrm{Na}^{+}$-independent, $\mathrm{Cl}^{-}$-dependent glutamate binding sites in rat hippocampal membranes is increased twoto fourfold after pre-exposing isolated membranes or hippocampal slices to high concentrations (0.1-10 mM) of L-glutamate or of glutamate analogs with high affinity for this binding site, such as quisqualate, homocysteate, or aminoadipate. $\mathrm{N}$-Methylaspartate and kainate are ineffective. A similar binding increase is induced by transient exposure to the dipeptide tyrosylglutamate. The newly induced binding sites appear to be identical with pre-existing $\mathrm{Cl}^{-}$-dependent binding sites by several criteria: They have a similar pharmacological profile, they are sensitive to low concentrations of $\mathrm{Na}^{+}$, and the number of sites can be further increased by transient exposure to micromolar calcium concentrations. Moreover, binding of [ $\left.{ }^{3} \mathrm{H}\right] \mathrm{APB}$, a ligand selective for the $\mathrm{Cl}^{-}$-dependent glutamate binding sites, is also increased after glutamate preincubation. The induction of binding sites by high glutamate concentrations, described herein, is calcium-independent, not inhibited by leupeptin and, therefore, different from the previously described activation of binding sites by a calcium-sensitive protease. The high concentration of ligand needed to induce increased binding suggests the presence in hippocampal membranes of a binding site with low, millimolar affinity that is functionally related to the known highaffinity binding sites. Several interpretations of the observed effects and their implications for the possible relationship between the binding site and the synaptic receptor are discussed.
\end{abstract}

An increasing body of evidence indicates that certain types of glutamate binding sites in brain synaptic membranes are affected by neurophysiological and behavioral manipulation. Thus longterm potentiation, a very long-lasting form of synaptic facilitation caused by brief periods of high-frequency stimulation, is accompanied by an increase in the number of these sites (Lynch et al., 1982). Similar effects have been found in the hippocampus after the induction of seizure proneness ("kindling") by repeated episodes of intense afferent stimulation (Savage et al., 1982), or following the learning of a conditioned response (Mamounas et al., 1984). In each of these cases, the experimental manipulation produces both a lasting modification of hippocampal physiology and a change in membrane glutamate binding sites. These changes seem to occur within one subgroup of glutamate binding sites, which is characterized by its dependence on $\mathrm{Cl}^{-}$and its high affinity for amino-phosphonobutyrate and quisqualate (Savage

\footnotetext{
Received June 20, 1984; revised May 20, 1985; accepted May 23, 1985.

This work was supported by Grants AFOSR-82-0116 to G.L. and BNS-8112156 to M.B.

Correspondence should be addressed to Dr. M. Kessler, Center for the Neurobiology of Learning and Memory, University of California, Irvine, Irvine, CA 92717.

Copyright $\odot 1986$ Society for Neuroscience $0270-6474 / 86 / 020355-09 \$ 02.00 / 0$
}

et al., 1982). Since there is evidence linking these binding sites to transmitter receptors (Baudry and Lynch, 1984; Fagg et al., 1982), it is not unreasonable to assume that the biochemical and physiological effects are causally related.

It is not known which aspects of physiological activity trigger the observed changes in putative receptors, but an accumulation of glutamate (or a related compound) in the synaptic zone is an attractive possibility. The initiating event for both long-term potentiation (LTP) and kindling is the rapid stimulation of a large contiguous group of fibers, a circumstance in which the capacity of the reuptake process might be exceeded by unusual amounts of released transmitter. This led us to test the effects of high concentrations of glutamate and several of its analogs on the number and affinity of glutamate binding sites. We have found that exposure of membrane preparations and in vitro hippocampal slices to these compounds results within minutes in the appearance of $\mathrm{Cl}^{-}$-dependent glutamate binding sites with characteristics comparable to those of basal sites. The implications of this finding for the understanding of the modulation of synaptic receptors and transmitter physiology will be discussed.

A preliminary report of some of the results has been presented (Baudry et al., 1981b).

\section{Materials and Methods}

\section{Preparation of membranes from rat hippocampus}

Two hippocampi were homogenized in a glass/Teflon homogenizer with a motor-driven pestle in $5 \mathrm{ml}$ of $0.32 \mathrm{M}$ sucrose and $1 \mathrm{~mm}$ EGTA/K $\mathrm{K}^{+}$ pH 6.8 (buffer S). The pellet $\Gamma_{2}$ (1st spin: $1000 \times g$ for $10 \mathrm{~min} ; 2$ nd spin: $27,000 \times g$ for $20 \mathrm{~min}$ ) was suspended in $5 \mathrm{ml}$ buffer $\mathrm{L}(5 \mathrm{~mm}$ Tris/ $\mathrm{HCl}, 1 \mathrm{~mm}$ EGTA $/ \mathrm{K}^{+}, \mathrm{pH} \mathrm{8.1),} \mathrm{sparing} \mathrm{the} \mathrm{brown} \mathrm{core} \mathrm{of} \mathrm{the}$ pellet, lysed for $40 \mathrm{~min}$ on ice, homogenized in a glass/Teflon homogenizer by three manual strokes, and spun for $20 \mathrm{~min}$ at $6000 \times \mathrm{g}$. The upper whitish layer of the pellet ("buffy coat") was resuspended in the supernatant and spun at $40,000 \times g$ for $20 \mathrm{~min}$. The resulting pellet was resuspended in $8 \mathrm{ml}$ of buffer T $(50 \mathrm{mM}$ Tris/ $\mathrm{HCl}, 50 \mu \mathrm{M}$ EGTA $\mathrm{K}^{+}, \mathrm{pH}$ 7.4) and dispersed with a tip sonicator at low power for 3 sec. The last centrifugation, with subsequent sonication, was repeated two more times. The final pellet was suspended in buffer $T$ to give a concentration of $150 \mu \mathrm{g}$ protein $/ \mathrm{ml}$. Aliquots of the suspension $(1.5 \mathrm{ml})$ were frozen at $-70^{\circ} \mathrm{C}$. All experiments were performed at least once with fresh membranes; frozen and fresh membranes gave qualitatively identical results, the only difference bcing a $10-40 \%$ reduction in the absolute amount of binding in frozen/thawed membranes.

\section{Binding assuys}

In the standard binding assay, $40 \mu \mathrm{l}$ of membrane suspension was mixed with $10 \mu \mathrm{l}$ of a solution containing $0.5 \mu \mathrm{M}\left[{ }^{3} \mathrm{H}\right] \mathrm{r}$-glutamate (ICN, Radiochemicals, $50 \mathrm{Ci} / \mathrm{mmol}$; final concentration, $100 \mathrm{nM}$ ) or $1 \mu \mathrm{M}$ [ $\left.{ }^{3} \mathrm{H}\right] A P B$ (2-amino-4-phosphonobutyric acid) (New England Nuclear, $26.1 \mathrm{Ci} / \mathrm{mmol}$, final concentration, $200 \mathrm{~nm}$ ). After $40 \mathrm{~min}$ incubation 

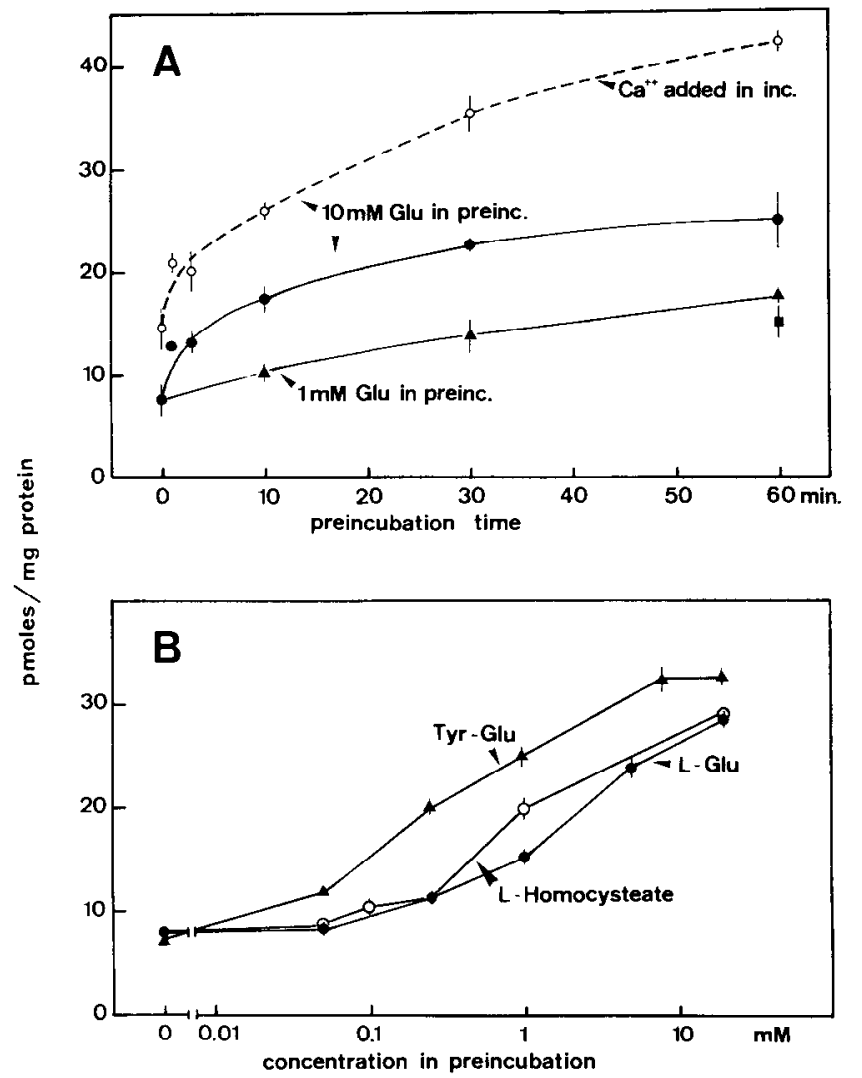

Figure 1. A. Freshly prepared hippocampal membranes were preincubated at $35^{\circ} \mathrm{C}$ with $10 \mathrm{~mm}(\mathrm{O}$, e) or $1 \mathrm{~mm}(\Delta) \mathrm{L}$-glutamate/Tris for the time indicated on the $x$-axis. The membranes were washed by four centrifugations and glutamate binding was assayed as described in Methods. Membranes preincubated in $10 \mathrm{~mm}$ glutamate were incubated both in the absence $(O)$ and presence $(O)$ of $0.5 \mathrm{mM} \mathrm{CaCl}_{2}$. One aliquot of membranes was preincubated in $10 \mathrm{~mm}$ glutamate at $0^{\circ} \mathrm{C}$ instead of $35^{\circ} \mathrm{C}(0)$. Bars indicate SEM of quadruplicate determinations. This figure shows a representative experiment. The average binding increase elicited by $10 \mathrm{mM}$ L-glutamate was $+187 \%(n=2)$ after 5 min and $+216 \pm 18 \%(n=12)$ after $10 \mathrm{~min}$ preincubation time. $B$, Dependence on concentration of inductants. Membranes were preincubated for 20 min at $35^{\circ} \mathrm{C}$ with L-glutamate $(\Theta)$, L-homocysteate $(\mathrm{O})$, or L-tyrosyl-Lglutamate (TG, $\Delta$ ) at the concentrations shown on the abscissa, and further processed as described in Methods.

at $35^{\circ} \mathrm{C}$ the sample was diluted with $3 \mathrm{ml}$ ice-cold $50 \mathrm{~mm}$ Tris $/ \mathrm{Cl}, \mathrm{pH}$ 7.4, and filtered through $0.45 \mu \mathrm{m}$ pore size Millipore filters. The filters were washed twice with the same ice-cold dilution medium. Nonspecific binding was determined in the presence of $1 \mathrm{~mm}$ unlabeled L-glutamate and subtracted from all binding values.

\section{Induction of new binding sites}

Aliquots of fresh or frozen/thawed membranes were incubated at 33$35^{\circ} \mathrm{C}$ with $0.1-20 \mathrm{~mm}$ concentrations of glutamate or glutamate analogs, which were added from stock solutions adjusted to neutral $\mathrm{pH}$ with Tris (variation of the pH during the preincubation of between 5.0 and 9.5 in the absence of glutamate did not affect binding; therefore, minor changes in $\mathrm{pH}$ during the preincubation cannot account for the observed changes in glutamate binding). To wash the membranes free of glutamate, the preparations were centrifuged $4 \times$ in a cooled $\left(4^{\circ} \mathrm{C}\right)$ Beckman airfuge at $130,000 \times g$ for $5 \mathrm{~min}$; in order to promote the release of any trapped or bound glutamate, the pellets were suspended in ice-cold buffer $\mathrm{T}$ by vigorous pipetting and left at $35^{\circ} \mathrm{C}$ for $5 \mathrm{~min}$ between spins. The final pellet was again resuspended in buffer $T$ and immediately used for the binding assay.

Preparation of slices and preincubation with glutamate analogs Transverse slices from rat hippocampi were cut at $400 \mu \mathrm{m}$ on a McIlwain tissue chopper. Each slice was transferred to a separate glass vial con- taining $0.6 \mathrm{ml}$ incubation medium (in mM: $\mathrm{NaCl}, 124 ; \mathrm{KCl}, 3.3 ; \mathrm{KH}_{2} \mathrm{PO}_{4}$, $1.25 ; \mathrm{MgSO}_{4}, 2.4 ; \mathrm{CaCl}_{2}, 3.1 ; \mathrm{NaHCO}_{3}, 26$; D-glucose, 10 ; urea, 2 ; $\mathrm{Na}$ ascorbate, 3 ), and was continuously gassed with $95 \% \mathrm{O}_{2} / 5 \% \mathrm{CO}_{2}$. The slices were incubated for $1 \mathrm{hr}$ at $35^{\circ} \mathrm{C}$ with gentle shaking. Slices treated in this way usually showed good electrophysiological responses when tested in a recording chamber. After the $60 \mathrm{~min}$ recovery period, L-glutamate or glutamate analogs were added from stock solutions adjusted to neutral $\mathrm{pH}$ with $\mathrm{NaOH}$. At the end of the incubation, the slices were transferred to ice-cold buffer $\mathrm{S}$ (see above) for about $5 \mathrm{~min}$ and homogenized in a $1 \mathrm{ml}$ glass/Teflon homogenizer in $200 \mu \mathrm{l}$ buffer $\mathrm{S}$ by 30 manual strokes. The homogenate was spun at $500 \times g$ for $5 \mathrm{~min}$ and the supernatant was centrifuged in a Beckman airfuge for $5 \mathrm{~min}$ $(130,000 \times g)$. The pellet $\mathrm{P}_{2}$ was suspended by vigorous pipetting in lysis buffer $\mathrm{L}$, left on ice for $20 \mathrm{~min}$, and centrifuged $3 \times$ for $5 \mathrm{~min}$ in the airfuge. After the first of these spins, the pellet was resuspended in buffer $\mathrm{L}$, and after the subsequent spins, in buffer $\mathrm{T}$. After the second spin, the resuspended membranes were warmed to $35^{\circ} \mathrm{C}$ for $5 \mathrm{~min}$. Membranes prepared with up to four additional centrifugations and additional $5 \mathrm{~min}$ incubations between spins gave essentially identical values for specific glutamate binding.

\section{Protein assay}

Protein was determined with the assay according to Bradford (1976), using BSA as standard. Aliquots of the membrane suspensions $(20 \mu \mathrm{l})$ were first mixed with $90 \mu \mathrm{l} 0.1 \mathrm{~N} \mathrm{NaOH}$ to make the membrane proteins more accessible to the dye, and then with $900 \mu$ l of the commercially available Bio-Rad reagent.

\section{Determination of residual glutamate and L-tyrosyl-L-glutamate by $H P L C$}

Membrane aliquots prepared from hippocampus plus cortex were incubated for $40 \mathrm{~min}$ with $10 \mathrm{mM}$ L-glutamate or L-tyrosyl-L-glutamate (TG) and washed as described above. One aliquot of the final suspension was used for a binding assay. The rest of the membranes were pelleted and resuspended in a small volume of $100 \mathrm{~mm} \mathrm{KCl}$. The protein was then precipitated by adding 2.5 volumes of ethanol, and spun down. Glutamate was determined in the supernatant by reverse-phase highperformance liquid chromatography (HPLC), using a prccolumn derivatization method with $o$-phthaldialdehyde (Lindroth and Mopper, 1979) and a $3 \mu \mathrm{m}$ ODS Spherisorb $10 \mathrm{~cm}, 4.6 \mathrm{~mm}$ ID column. The HPLC equipment consisted of a Spectra-Physics Model 8700 pump, a Kratos FS-950 fluorimeter, and a HP 3390A recording integrator. TG was determined by electrochemical detection of the tyrosyl phenolic group using a LC-4 amperometric controller (Bioanalytical Systems) set at 1.0 $\mathrm{V}$ and a mobile phase consisting of $6.8 \mathrm{gm}$ sodium phosphate (monobasic), $6.9 \mathrm{gm}$ sodium acetate, and $0.9 \mathrm{gm}$ sodium lauryl sulfate (Sigma) in 1 liter of $75 \%$ distilled water and $25 \%$ acetonitrile, adjusted to $\mathrm{pH} 3$ with phosphoric acid. The same HPLC pump, ODS column, and integrator were used.

\section{Results}

Transient exposure to glutamate increases

\section{$\left[{ }^{3} \mathrm{H}\right]_{L}$-glutamate binding}

Specific binding of $\left[{ }^{3} \mathrm{H}\right]$ glutamate to hippocampal membranes was increased three- to fourfold when the membranes were preincubated for several minutes in millimolar concentrations of glutamate (Fig. 1 $A$ ). The minimum glutamate concentration necessary in the preincubation to induce a noticeable binding increase was in the order of $100 \mu \mathrm{M}$, while concentrations of about $10 \mathrm{~mm}$ were required to obtain maximum effect (Fig. $1 B$ ). At the latter concentration, half-maximal activation was obtained with preincubation times of $5 \mathrm{~min}$ or less. This binding increase was a highly reliable phenomenon; the average increase in all the experiments where membranes were exposed to 10 mM L-glutamate for 5-30 min was $+370 \%(n=45)$; the binding increase was in no case less than $+60 \%$, and only in three cases less than $+130 \%$.

After preincubation, the membranes were extensively washed by four centrifugations. Careful washing was mandatory in these experiments, since the concentration of free glutamate had to be lowered from $10 \mathrm{~mm}$ to less than $100 \mu \mathrm{M}$ in order to avoid 
Table 1. Sensitivity of glutamate-induced binding sites to $\mathrm{Cl}^{-}, \mathrm{Na}^{+}$, and Saponin

$\left[{ }^{3} \mathrm{H}\right]$ glutamate bound (mean $\pm \mathrm{SD}$ ) (pmol/mg protein)

\begin{tabular}{llc}
$\begin{array}{l}\text { Composition of the } \\
\text { incubation medium }\end{array}$ & $\begin{array}{l}\text { "Standard" } \\
\text { binding }\end{array}$ & $\begin{array}{l}\text { Binding after } \\
\text { glutamate } \\
\text { induction }\end{array}$ \\
\hline $0 \mathrm{mM} \mathrm{Cl}^{-}, 0.3 \mathrm{~mm} \mathrm{APB}$ & $0.96 \pm 0.07$ & $2.7 \pm 0.1$ \\
$30 \mathrm{mM} \mathrm{Cl}^{-}$ & $10.2 \pm 0.1$ & $40.1 \pm 2.2$ \\
$30 \mathrm{mM} \mathrm{Cl},+2 \mathrm{~mm} \mathrm{Na}$ & $2.7 \pm 0.1$ & $9.0 \pm 0.3$ \\
$30 \mathrm{mM} \mathrm{Cl}-,+10 \mathrm{mM} \mathrm{Na}^{+}$ & $1.66 \pm 0.1$ & $2.3 \pm 0.3$
\end{tabular}

After transient exposure to Saponin:
$0 \mathrm{~mm} \mathrm{Cl}^{-}, 0.3 \mathrm{~mm}$ APB
$1.19 \pm 0.07$
$1.15 \pm 0.05$
$30 \mathrm{mM} \mathrm{Cl}^{-}$
$1.62 \perp 0.05$
$2.13 \perp 0.22$

Membranes were preincubated for $30 \mathrm{~min}$ without (for "standard" binding) or with $10 \mathrm{~mm}$ L-glutanate and washed $4 \times$ in $50 \mathrm{~mm}$ MES/Tris, $50 \mu \mathrm{M}$ EGTA, pII 7.4. $\mathrm{KCl}(30 \mathrm{~mm})$ and $\mathrm{Na}$-acetate $(2$ or $10 \mathrm{~mm})$ were added to the incubation medium, as indicated in the table. APB was added to the $\mathrm{Cl}^{-}$-free media to suppress residual $\mathrm{Cl}^{-}$-dependent binding (Fagg et al., 1983). Aliquots of the membranes were incubated with $0.02 \%$ Saponin for $20 \mathrm{~min}$ at $35^{\circ} \mathrm{C}$. The membranes were then washed free of the detergent by two centrifugations, resuspended in MES/ Tris buffer and used for the binding assay. This detergent treatment solubilized less than $10 \%$ of the membrane protein. $\mathrm{Cl}^{-}$-dependent glutamate binding was similarly sensitive to low concentrations of other detergents, such as Triton X-100 $(0.01 \%)$. The table shows a representative experiment. All parts of the experiment were performed at least $4 \times$ with essentially identical results.

interference with the binding assay. We have routinely used four centrifugations, although three centrifugations proved to be sufficient, and additional centrifugations up to a total of eight had no effect on the magnitude of specific binding. After each centrifugation, the membranes were left for $5 \mathrm{~min}$ at $35^{\circ} \mathrm{C}$ to promote release of bound or trapped glutamate.

The induced sites are $\mathrm{Cl}^{-}$-dependent, $\mathrm{APB}$-sensitive glutamate binding sites

The observed stimulation of glutamate binding resulted entirely from an increase in the number of sites and not from a change in the affinity for glutamate (Fig. 2). The $K_{d}$ value of $0.95 \mu \mathrm{M}$ and the Hill coefficient of 0.98 are in good agreement with values reported for glutamate binding by various authors (Foster and Fagg, 1984). Glutamate binding measured after induction displayed all the characteristics of one subclass of glutamate binding sites, typified by strict dependence on $\mathrm{Cl}^{-}$(a detailed description of these sites is given in Fagg ct al., 1982, 1983; Mcna et al., 1982; Monaghan et al., 1983): (1) Binding was reduced by more than $90 \%$ when $\mathrm{Cl}^{-}$was omitted from the incubation medium (Table 1). (2) Binding was increased up to twofold after exposure to micromolar concentrations of $\mathrm{Ca}^{2+}$ (Fig. 1A). (3) Binding was inhibited by millimolar concentrations of $\mathrm{Na}^{+}(\mathrm{Ta}-$ ble 1). (4) Quisqualate, homocysteate, and D- and L-aminoadipate inhibited glutamate binding with a potency similar to that of L-glutamate itself (Table 2). D-Glutamate and L- and D-aspartate had 5-50 $\times$ lower affinities. N-Methyl-DL-aspartate (NMA) and kainate were ineffective in displacing glutamate binding. APB was clearly preferred over the analog 2-amino-5phosphonovaleric acid (APV), which is believed to interact preferentially with the NMDA receptor. This pharmacological profile is congruent with that reported for the $\mathrm{Cl}^{-}$-dependent glutamate binding site (Fagg et al., 1983; Foster and Fagg, 1984). (5) Binding of $\left[{ }^{3} \mathrm{H}\right] \mathrm{APB}$ was increased in membranes preincubated in $10 \mathrm{~mm}$ glutamate (Fig. $3 B$ ). Using tritium-labeled APB, Monaghan et al. (1983) demonstrated that APB interacts selectively with the $\mathrm{Cl}^{-}$-dependent glutamate binding site. (6) Binding was very sensitive to even low concentrations of detergents, which are in themselves insufficient to solubilize membranes;

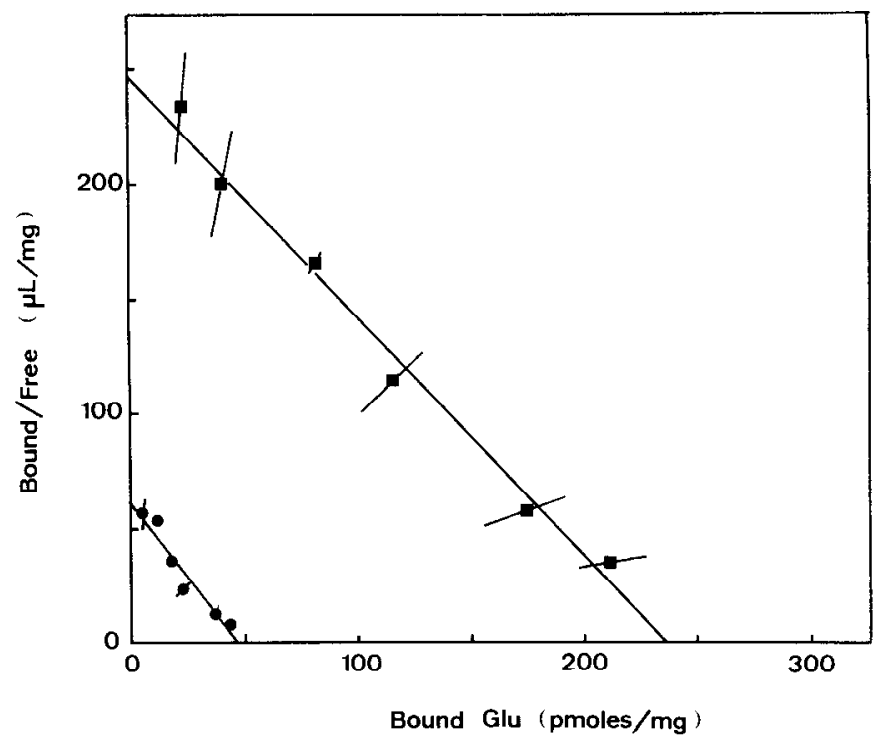

Figure 2. Scatchard plot of basal binding and after induction of glutamate binding sites. Aliquots of the membrane preparation were preincubated with $0(0)$ or $10 \mathrm{~mm}(\square)$ L-glutamate for $20 \mathrm{~min}$. The Scatchard plot was determined from glutamate binding at $0.1,0.2,0.5,1,3$, and $6 \mu \mathrm{M}$ glutamate. The bars represent the SD of duplicate or triplicate measurements. Nonspecific binding was determined in the presence of $1 \mathrm{~mm}$ glutamate and subtracted from all binding values. The Hill coefficients were 1.03 for untreated membranes and 0.98 for glutamate preincubated membranes. $-\mathrm{a}, K_{\mathrm{d}}=0.95 \mu \mathrm{M} ; B_{\max }=236 \mathrm{pmul} / \mathrm{mg}$. $\longrightarrow, K_{\mathrm{d}}=0.73 \mu \mathrm{M} ; B_{\max }=46 \mathrm{pmol} / \mathrm{mg}$.

transient exposure to $0.02 \%$ Saponin irreversibly inactivated binding (Table 1); the $\mathrm{Cl}^{-}$-dependent glutamate binding site in untreated and in glutamate-preincubated membranes was found to be similarly sensitive to low concentrations of Triton X-100, Digitonin, and other detergents (data not shown).

\section{Binding-site induction by glutamate analogs}

The ability to generate new binding sites was not confined to L-glutamate. All glutamate analogs that can displace ['II]glutamate from the $\mathrm{Cl}^{-}$-dependent high-affinity binding sites were also capable of inducing new binding sites, and vice versa, with the single exception of TG (see below), and the order of potency of all the analogs tested appeared to be about the same under both conditions, quisqualate, homocysteate, and aminoadipatc bcing the most potent inducers aside from L-glutamate itself (Fig. 4; compare with Table 2). However, the concentrations required to induce new sites were consistently in the millimolar range and thus about a factor of 1000 higher than the apparent affinities for the high-affinity binding site. NMA and kainate, two analogs that interact selectively with $\mathrm{Cl}^{-}$-independent binding sites, did not induce a binding increase; instead they regularly caused a slight depression of glutamate binding.

Considering the high degree of correlation between the pharmacological profiles, it is of particular interest that binding-site induction differed from high-affinity glutamate binding in two aspects: (1) Binding-site induction did not require the presence of $\mathrm{Cl}^{-}$and (2) it was not inhibited by $\mathrm{Na}^{+}$even at concentrations that completely abolished $\mathrm{Cl}^{-}$-dependent glutamate binding (Table 3).

\section{Binding-site induction by L-tyrosyl-L-glutamate}

TG induced new binding sites with a higher potency than did glutamate or any of the above-mentioned glutamate analogs (Fig. $1 B$ ), although it did not seem to interact with the highaffinity glutamate binding site itself, even when present at a concentration of $10 \mathrm{mM}$ during the incubation with 
Figure 3. Binding of $\left[{ }^{3} \mathrm{H}\right]$ aminophosphonobutyrate (APB). $A$, Increased $\left[{ }^{3} \mathrm{H}\right] \mathrm{APB}$ binding in the presence of TG. Membranes were incubated for $60 \mathrm{~min}$ with $0.1 \mu \mathrm{M}$ $\left[{ }^{3} \mathrm{H}\right.$ ]glutamate $(\bullet)$ or $0.2 \mu \mathrm{M}\left[{ }^{3} \mathrm{H}\right] \mathrm{APB}$ ( $\square$ ) in the presence of the TG concentrations given on the abscissa. The figure shows means and SEM of triplicate determinations. $B$, Induction of $\left[{ }^{3} \mathrm{H}\right] \mathrm{APB}$ binding sites by glutamate and $T G$. Membranes were preincubated for $30 \mathrm{~min}$ at $35^{\circ} \mathrm{C}$ with no further addition (left column $=100 \%$ ), with $10 \mathrm{mM}$ L-glutamate (middle column), or with $5 \mathrm{~mm}$ TG (right col$u m n$ ), washed by four centrifugations and incubated with $0.2 \mu \mathrm{M}\left[{ }^{3} \mathrm{H}\right] \mathrm{APB}$ for $60 \mathrm{~min}$. Means and SEM are shown for six experiments with three different membrane preparations.
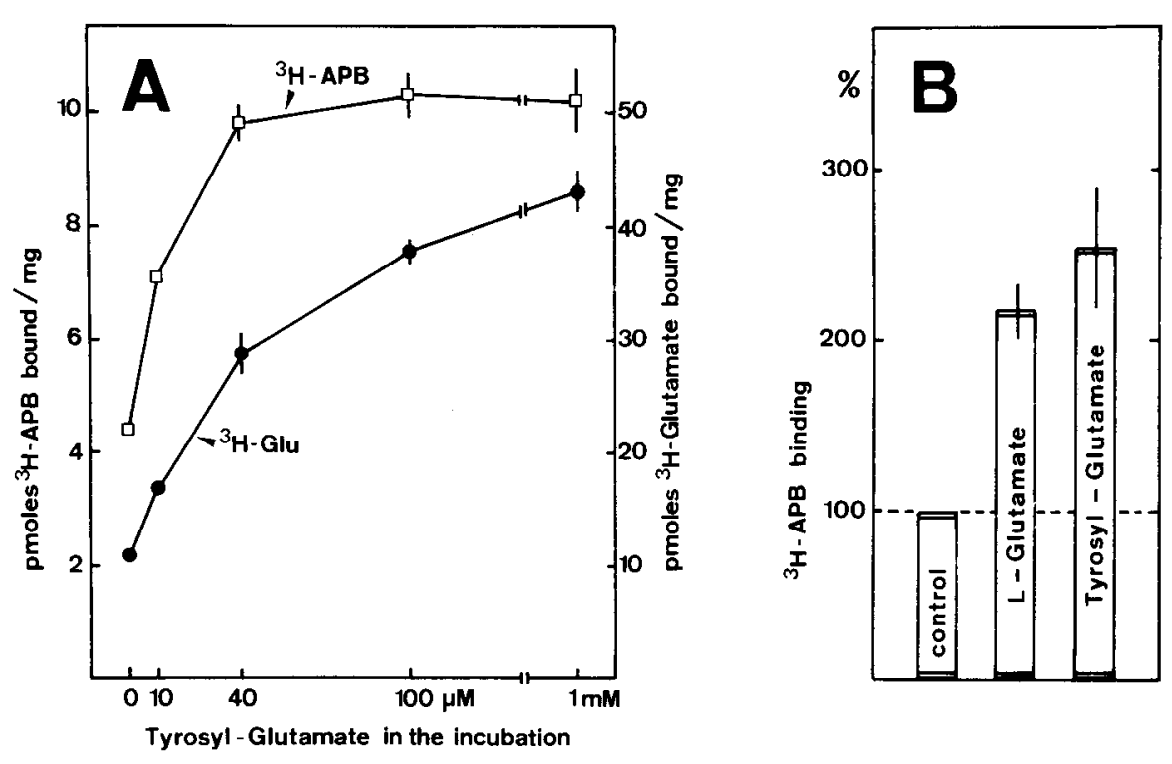

$\left[{ }^{3} \mathrm{H}\right]$ glutamate. Ferkany et al. $(1983,1984)$ have reported that several glutamyldipeptides increase $\left[{ }^{3} \mathrm{H}\right]$ glutamate binding when present in the binding incubation; they suggested that these peptides may control the number of available glutamate binding sites through a second, modulatory binding site. The use of a $\mathrm{Cl}^{-}$-free buffer for their incubations suggested that TG regulated one of the $\mathrm{Cl}^{-}$-independent glutamate binding sites, but we have found that binding increase in the presence of $\mathrm{Cl}^{-}$is much more pronounced than in its absence, and also that the pharmacological profile of $\left[{ }^{3} \mathrm{H}\right]$ glutamate binding in the presence of TG and $\mathrm{Cl}^{-}$strongly resembles that for $\mathrm{Cl}^{-}$-dependent binding (not shown). Moreover, TG, when added to the incubation medium,

Table 2. Pharmacological profile of glutamate binding after inducation of new glutamate binding sites

\begin{tabular}{llr} 
Glutamate analog tested & $\begin{array}{l}K_{\mathrm{d}}(\mu \mathrm{M}) \\
(\mathrm{m}) a n \text { and SEM) }\end{array}$ & $(n)$ \\
\hline Quisqualate & $0.86 \pm 0.11$ & 8 \\
L-Glutamate & $1.05 \pm 0.13$ & 10 \\
D-Glutamate & $14.5 \pm 4.0$ & 5 \\
L-Homocysteate & $1.45 \pm 0.30$ & 5 \\
D-Homocysteate & $2.34 \pm 0.37$ & 4 \\
l-Aminoadipate & $1.12 \pm 0.14$ & 5 \\
D-Aminoadipate & $2.33 \pm 0.32$ & 5 \\
L-Aspartate & $20.0 \pm 4.1$ & 7 \\
D-Aspartate & $69.1 \pm 11.7$ & 6 \\
APB (2-amino-4-phosphonobutyric acid) & $9.8 \pm 1.4$ & 5 \\
APV (2-amino-5-phosphonovaleric acid) & $54 \pm 17$ & 4 \\
GDEE (glutamate-diethylester) & $580 \pm 100$ & 6 \\
NMA (N-methyl-DL-aspartate) & $284 \pm 53$ & 6 \\
Kainate & $>1000$ & 6
\end{tabular}

Membranes were preincubated for $30 \mathrm{~min}$ with $10 \mathrm{~mm}$ glutamate and washed as usual. Binding was determined without ligand added and at two or three concentrations of the listed glutamate analogs. The glutamate analogs were added to the membranes $15 \mathrm{~min}$ before addition of $0.1 \mu \mathrm{M}\left[{ }^{3} \mathrm{H}\right]$ glutamate. The $K_{\mathrm{d}}$ value was determined from the intersection of the regression line of $1 /$ bound glutamate vs ligand concentration and the horizontal line at $1 / B_{\max }, n$ is the number of independent $K_{\mathrm{d}}$ determinations, most of them done on separate membrane preparations. In some experiments the membranes were suspended in $50 \mathrm{~mm}$ MES/Tris, pH \% $7,20 \mathrm{~mm} \mathrm{KCl}, 50 \mu \mathrm{M} \mathrm{EG'IA}$ instead of buffer 'T; the $K_{d}$ values obtained were not dependent on the choice of buffer. also caused an increased binding of $\left[{ }^{3} \mathrm{H}\right] \mathrm{APB}$ (Fig. $3 \mathrm{~A}$ ), which appears to bind selectively to the $\mathrm{Cl}^{-}$-dependent site. Whether only one or several glutamate binding sites are regulated through $\mathrm{TG}$, or whether the $\mathrm{Cl}^{-}$-dependent site is identical with one of the sites measured in the absence of $\mathrm{Cl}^{-}$, possibly with a different pharmacological profile, remains to be elucidated.

Induction of glutamate binding by $\mathrm{TG}$, as shown in Figure $1 B$, showed a high degree of similarity with induction by glutamate itself. The maximum inducible increase was the same in both cases and was not additive when membranes were exposed to $10 \mathrm{~mm}$ glutamate and TG simultaneously or sequentially; however, calcium, when added to the incubation medium, doubled glutamate binding both in glutamate and in TG-preincubated membranes (not shown). In addition, membranes preincubated with TG maintained an increased number of binding sites for hours after washing, as is the case for glutamatetreated membranes. Experimentation with TG is subject to a possible error not encountered with glutamate induction: Whereas incomplete removal of glutamate during the wash procedure would lead to an apparent reduction of binding in the binding assay, residual $\mathrm{TG}$ might stimulate glutamate binding directly through its presence in the incubation. However, the amount of $1.1 \pm 0.7 \mathrm{nmol} / \mathrm{mg}$ protein $(n=6)$ of residual TG determined in washed membranes via separation on HPLC could give a concentration of about $0.22 \mu \mathrm{M}$ free $\mathrm{TG}$ in the binding assay incubation, which is too far below the $\mathrm{EC}_{50}$ of $11 \mu \mathrm{M}$ (Ferkany et al., 1984) to cause a significant binding increase. Moreover, the percentage increase in binding in TG-preincubated membranes was the same at protein concentrations ranging from 6.5 to $260 \mu \mathrm{g} / \mathrm{ml}$; at the lowest protein concentration, free $\mathrm{TG}$, as determined by HPLC, could maximally be $8 \mathrm{~nm}$.

\section{Reversibility of induced glutamate binding}

The induced binding increase lasted for hours after removal of glutamate (Table 4A). Binding decreased for the average of four experiments by only $26 \%$, if glutamate-treated and -washed membranes were kept for $2 \mathrm{hr}$ at $35^{\circ} \mathrm{C}$ prior to the binding assay. However, exposure to $\mathrm{Na}^{+}$after washing out glutamate caused a reversion to very low values for glutamate binding (Table 4B). A subsequent second exposure of $\mathrm{Na}^{+}$-treated membranes to 10 mM glutamate restored glutamate binding to high levels similar to those following the first glutamate exposure, which suggests the possibility that $\mathrm{Na}^{+}$and high concentrations of glutamate excrt a reversible, antagonistic cffect on the state of the glutamate binding sites in these membranes. 


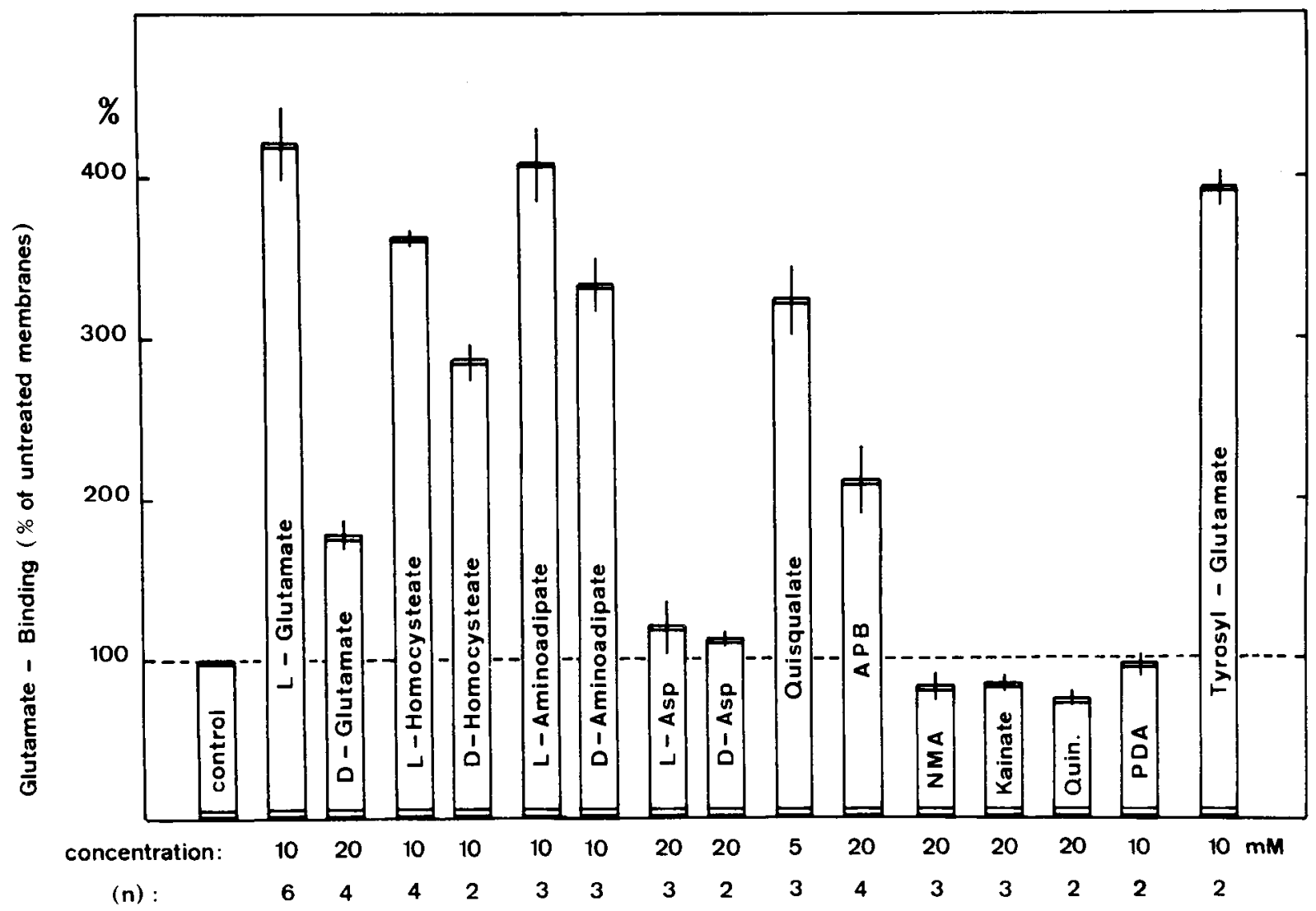

Figure 4. Potency of glutamate analogs to induce new glutamate binding sites. Freshly prepared membranes were suspended after the final centrifugation in $50 \mathrm{~mm}$ triethanolamine/HCl, pH 7.4, and $50 \mu \mathrm{M}$ EGTA. Glutamate and glutamate analogs were added to the membranes from stock solutions preadjusted to neutral $\mathrm{pH}$ with Tris, with the final concentration shown underneath the figure. The membranes were incubated with the various glutamate analogs for $20 \mathrm{~min}$ at $35^{\circ} \mathrm{C}$, washed by four centrifugations, and incubated with [ $\left.{ }^{3} \mathrm{H}\right] \mathrm{glutamate}$, as described in Methods. Glutamate binding in membranes not exposed to any ligand during the preincubation (control) was $7.9 \mathrm{pmol} / \mathrm{mg}$ protein (mean of nine determinations). Binding in the other membrane samples (mean and SEM) is expressed as percentage relative to binding in control membranes. The experiments were done on three different membrane preparations, the number of experiments $(n)$ for each inductant being shown underneath the figure. The triethanolamine buffer was chosen for this experiment in order to provide an increased buffer capacity in the preincubation medium. It was further demonstrated (data not shown) that both glutamate binding in control membranes and induction by glutamate are little affected by varying the $\mathrm{pH}$ during the preincubation period between 6.8 and 7.8 , thus making it unlikely that the differences in the potencies to induce glutamate binding arise from some small variations of the $\mathrm{pH}$. $A P B, 2$-Amino-4-phosphonobutyric acid; NMA, N-methyl-DL-aspartate; Quin., quinolinate; $P D A$, cis-2,3-piperidine dicarboxylate.

\section{Some tests for possible mechanisms of binding-site induction}

The protease inhibitor leupeptin did not influence the bindingsite induction by glutamate or TG (Table 3). Moreover, in membranes in which glutamate binding had been maximally stimulated by a 60 min preincubation with $10 \mathrm{~mm}$ glutamate, calcium could still activate further glutamate binding sites (Fig. $1 A$ ). Inclusion of calcium in the preincubation with glutamate similarly increased glutamate binding (Table 3 ). These data suggest that binding-site induction by glutamate is based on a mechanism different from that for the calcium-induced binding increase.

No substance has yet been found which inhibits binding-site induction without permanently decreasing glutamate binding itself (as do thiol reagents). The protein phosphatase inhibitors $\mathrm{Zn}^{2+}$ and $\mathrm{F}^{-}$have only minimally affected binding-site induction (Table 3). GTP and its non-hydrolyzable analog, Gpp(NH)p, did not cause any change in $\mathrm{Cl}^{-}$-dependent glutamate binding, nor did they inhibit the induction of binding sites by glutamate or TG (not shown).

\section{Induction of binding sites in hippocampal slices}

A marked increase in glutamate binding could also be elicited in intact hippocampal slices if they were incubated in a medium containing millimolar concentrations of $\mathrm{L}$-glutamate, homocysteate, or other analogs, including TG (Table 5). Time course, concentration dependence, and pharmacological profile of binding-site induction in slices were similar to what has been described above for isolated hippocampal membranes. It is noteworthy that exposure of slices to $50 \mathrm{~mm} \mathrm{~K}^{+}$, which would presumably lead to transmitter release and massive ion fluxes, did not elicit an increase in binding. An important question, which necessarily complicates the interpretation of biochemical studies of slices, concerns the locus of the observed effects. Slices contain apparently intact, as well as damaged, neurons (Lee et al., 1981), and either or both could contribute to the results described above.

\section{Discussion}

\section{Characterization of induced binding sites}

Transient exposure of hippocampal membranes to millimolar concentrations of glutamate caused an increase in the number of glutamate binding sites, typically from about 50 to more than $200 \mathrm{pmol} / \mathrm{mg}$ protein. Scatchard-plot analysis in glutamatepreincubated membranes revealed only one binding site, with a dissociation constant $K_{\mathrm{d}}$ of about $1 \mu \mathrm{M}$, a value not significantly different from the $K_{\mathrm{d}}$ of basal glutamate binding (Fig. 2), and a Hill coefficient close to 1 . However, it has become increasingly clear during the past years that several different $\mathrm{Na}^{+}$-independent binding sites with similar dissociation constants for glu- 


\section{Table 3. Effect of leupeptin and various ions on the generation of} glutamate binding sites

\section{Composition of medium}

during preincubation

$\%$ Increase in $($ mean \pm SEM) glutamate binding
A. $10 \mathrm{~mm}$ glutamate plus
Buffer $\mathrm{T}$
Buffer $\mathrm{T}+1 \mathrm{~mm}$ leupeptin
Buffer $\mathrm{T}+20 \mathrm{~mm} \mathrm{NaCl}$
$+215 \pm 14 \%$
$+215 \pm 5 \%$
Buffer $\mathrm{T}+50 \mathrm{~mm} \mathrm{NaF} / 1 \mathrm{~mm}$ EDTA
$+245 \pm 11 \%$
Buffer $\mathrm{T}+100 \mu \mathrm{M} \mathrm{Zn}$ acetate
$+185 \pm 9 \%$
$+124 \pm 15 \%$
Buffer $\mathrm{T}+0.5 \mathrm{mM} \mathrm{CaCl}_{2}$
Buffer $\mathrm{T}+10 \mathrm{~mm} \mathrm{MgCl}_{2}$
$+329 \pm 11 \%$
$+183 \pm 19 \%$
B. $10 \mathrm{~mm}$ glutamate plus
PIPES buffer $\left(\mathrm{Cl}^{-}\right.$-free $)$
PIPES buffer $+20 \mathrm{~mm} \mathrm{KCl}$
$+133 \pm 10 \%$
$+137 \pm 13 \%$
$+110 \pm 10 \%$

Membranes were incubated for $10 \mathrm{~min}$ at $34^{\circ} \mathrm{C}$ in the solutions indicated above. Buffer T: $50 \mathrm{~mm}$ Tris/HCl, $50 \mu \mathrm{M}$ EGTA, pH 7.4; 1,4-piperazine-diethane sulfonic acid (PIPFS) buffer: $50 \mathrm{~mm}$ PIPFS/Tris, $50 \mu \mathrm{M}$ FGTA, $\mathrm{nH} 7.4$. Binding in control membranes was $7.2 \mathrm{pmol} / \mathrm{mg}$ protein. Induction in solutions containing Good buffers such as PIPES, HEPES, MOPS, or MES was consistently somewhat reduced as compared to that in Tris/ $\mathrm{HCl}$ or triethanolamine/ $\mathrm{HCl}$ buffers, which is possibly due to some weak interaction of these zwitterionic buffers with the glutamate binding sites. The numbers shown are from a representative experiment done on one membrane preparation. All tests were done $3-6 \times$ on different membrane preparations, giving essentially identical results.

tamate are present in hippocampal membranes. Werling et al., (1983) proposed the existence of two binding sites that can be discriminated by a large difference in their affinities to quisqualate. Mena et al. (1982) similarly suggested that glutamate binding is composed of at least two components, one of which, tentatively identified by these authors to be the synaptic receptor, is strictly dependent on $\mathrm{Cl}^{-}$, inhibited by $\mathrm{Na}^{+}$, activated by $\mathrm{Ca}^{2+}$, and binds selectively the glutamate analog APB. Using these criteria, $50-80 \%$ of glutamate binding in untreated membranes and more than $90 \%$ of such binding in glutamate-preincubated membranes is to these $\mathrm{Cl}^{-}$-dependent binding sites, which suggests that most of the newly induced sites are of the $\mathrm{Cl}$-dependent, APB-sensitive type. Binding to $\mathrm{Cl}^{-}$-independent sites was somewhat elevated in glutamate-preincubated membranes (Table 1), but it has not yet been determined if this was due to some residual binding to $\mathrm{Cl}^{-}$-dependent sites or whether binding to one of the $\mathrm{Cl}^{-}$-independent sites was also modified by the glutamate preincubation.

\section{The number of $\mathrm{Cl}^{-}$-dependent glutamate binding sites can he increased by at least two different mechanisms}

Transient exposure of synaptic membranes to calcium has been shown to lead to an increase in the number of $\mathrm{Cl}^{-}$-dependent glutamate binding sites, which persists after calcium is removed from the medium by EGTA (Baudry and Lynch, 1980; Baudry et al., 1981a, 1983). This activation does not seem to be caused by a direct interaction between calcium and the binding protein, since it can be completely suppressed by leupeptin, a tripeptide that inhibits a calcium-activated protease present in these membranes and that has by itself no effect on glutamate binding.

One important conclusion from these earlier studies was that synaptic membranes contain a reservoir of binding sites that normally are not expressed without appropriate pretreatment. This report provides further evidence that binding measurements in freshly prepared membranes underestimate the overall number of $\mathrm{Cl}^{-}$-dependent glutamate binding sites potentially
Table 4. Reversibility of binding-site induction

$\mathrm{pmol} / \mathrm{mg}$

Protein

bound

(mean \pm

Preincubation scheme SEM)

A. Reversibility at $35^{\circ} \mathrm{C}$ after removal of L-glutamate

1. No glutamate exposure, membranes on ice during preincubation period

$6.1 \pm 0.1$

2. No glutamate exposure, membranes at $35^{\circ} \mathrm{C}$ during the $140 \mathrm{~min}$ preincubation

3. Membranes at $35^{\circ} \mathrm{C}$ for $120 \mathrm{~min}$, then exposed to $10 \mathrm{~mm}$ glutamate for $20 \mathrm{~min}$

4. Membranes exposed to $10 \mathrm{~mm}$ glutamate for $20 \mathrm{~min}$, washed and incubated at $35^{\circ} \mathrm{C}$ for 120 min in glutamate-free medium

$19.1 \pm 0.3$

B. Reversal of binding-site induction by exposure to $\mathrm{Na}^{+}$

1. No glutamate exposure

$7.3 \pm 0.4$

2. After exposure to $10 \mathrm{~mm}$ glutamate

$36.5 \pm 0.7$

3. After glutamate exposure and subsequent 20 min exposure to $50 \mathrm{mM} \mathrm{Na}^{+}$(followed by seven washes)

$6.1 \pm 0.2$

4. After glutamate exposure, subsequent $\mathrm{Na}^{+}$ exposure and a second exposure to $10 \mathrm{~mm}$ glutamate

$22.6 \pm 1.3$

A. Membranes were incubated without $(2)$ or with $(3,4) 10 \mathrm{~mm}$ glutamate at $35^{\circ} \mathrm{C}$ for $20 \mathrm{~min}$, then washed by two centrifugations, resuspended and further incubated in glutamate-free buffer $\mathrm{T}$ for $100 \mathrm{~min}$ at $35^{\circ} \mathrm{C}$. Glutamate $(10 \mathrm{~mm})$ was then added to sample 3 and the incubations continued for $20 \mathrm{~min}$. All four samples were then washed by four centrifugations and immediately used for the binding assay. In the experiment shown, each condition was run in duplicate. The experiment was repeated three more times. The average loss of induced binding sites in all four experiments caused by the $120 \mathrm{~min}$ postincubation (condition 4 compared to condition 3) was $26 \%$. B. All samples were incubated for $20 \mathrm{~min}$ without (1) or with (2-4) $10 \mathrm{~mm}$ glutamate. Samples 1 and 2 were then washed by five centrifugations. Samples 3 and 4 were washed twice, then incubated for $10 \mathrm{~min}$ with $50 \mathrm{mM} \mathrm{NaCl}\left(\right.$ at $35^{\circ} \mathrm{C}$ ) and washed three more times. Both samples were then incubated again in the absence (3) or presence (4) of $10 \mathrm{~mm}$ glutamate for $20 \mathrm{~min}$, washed by four additional centrifugations as usual, and immediately used for the binding assay. The experiment was repeated $3 \times$ with identical results.

present in hippocampal membranes. In membranes transiently exposed to millimolar glutamate concentrations, the number of sites typically increased to more than $200 \mathrm{pmol} / \mathrm{mg}$ protein, and if these membranes were further exposed to calcium (together with or subsequent to glutamate exposure), the number of binding sites reached values of $300-500 \mathrm{pmol} / \mathrm{mg}$ protein. Thus, only about $10-15 \%$ of all the potentially available binding sites are expressed in untreated membranes.

Calcium- and glutamate-treated membranes are particularly well suited for the study of the kinetic and pharmacological properties of $\mathrm{Cl}^{-}$-dependent binding sites, since all the $\mathrm{Cl}^{-}$-independent binding sites together (NMDA site, quisqualate site, and kainate site) account for only $5 \%$ or less of total binding. Moreover, membranes thus enriched in $\mathrm{Cl}^{-}$-dependent binding sites might be the material of choice for starting the isolation of the glutamate binding protein.

The induction of new glutamate binding sites - the subject of this report-and the previously described activation by calcium must be based on different mechanisms. Glutamate induction proceeds in calcium-free media and is not inhibited by the protease inhibitor, leupeptin. The two mechanisms are additive, i.e., the stimulation that can be achieved by a combination of these two treatments is larger than the maximal stimulation that can be induced by either calcium or glutamate preincubation 
Table 5. Generation of glutamate binding sites in hippocampal slices

\begin{tabular}{|c|c|c|c|c|}
\hline Agent-tested & $\begin{array}{l}\text { Concen- } \\
\text { tration } \\
(\mathrm{m})\end{array}$ & $\begin{array}{l}\text { Exposure } \\
\text { time }\end{array}$ & $\begin{array}{l}\% \text { Increase (mean with } \\
\text { SEM or range) }\end{array}$ & $\begin{array}{l}\text { Number } \\
\text { of } \\
\text { slices } \\
\text { tested }\end{array}$ \\
\hline DL-Homocysteate & 1 & $5 \mathrm{~min}$ & $38 \pm 19 \%$ & 4 \\
\hline DL-Homocysteate & 5 & $5 \mathrm{~min}$ & $81 \pm 11 \%$ & 17 \\
\hline DL-Homocysteate & 5 & $10 \mathrm{~min}$ & $130 \pm 22 \%$ & 5 \\
\hline L-Glutamate & 10 & $5 \mathrm{~min}$ & $68 \% / 124 \%$ & 2 \\
\hline D-Aminoadipate & 6 & $30 \mathrm{~min}$ & $142 \% / 177 \%$ & 2 \\
\hline NMA & $1-5$ & $10-20 \mathrm{~min}$ & $-3 \%(-18$ to $+14 \%)$ & 8 \\
\hline Kainate & $0.1-0.2$ & $5-10 \mathrm{~min}$ & $-20 \%(-30$ to $-14 \%)$ & 4 \\
\hline Kainate & $1-5$ & $10-20 \mathrm{~min}$ & $-12 \%(-17$ to $0 \%)$ & 3 \\
\hline L-Tyrosyl-L-glutamate (TG) & 5 & $30 \mathrm{~min}$ & $65 \pm 16 \%$ & 7 \\
\hline $\mathrm{K}^{+}$ & 50 & $10-20 \mathrm{~min}$ & $-9 \%(-20$ to $+16 \%)$ & 5 \\
\hline \multicolumn{5}{|c|}{$\begin{array}{l}\text { Reduction of homocysteate-elicited binding increase by } \\
5 \mathrm{mM} \text { leupeptin }\end{array}$} \\
\hline
\end{tabular}

Hippocampal slices were gently shaken in glass vials in $0.6 \mathrm{ml}$ of continuously gassed medium at $33^{\circ} \mathrm{C}$ for $1 \mathrm{hr}$. The agents indicated in the table were then added from 20-fold concentrated stock solutions, previously adjusted to neutral $\mathrm{pH}$ with $\mathrm{NaOH}$. At the end of the incubation period, the slices were transferred into ice-cold buffer $\mathrm{S}$ and homogenized. Membranes were prepared in a scaled-down isolation procedure and immediately used for the glutamate binding assay (for further details, see Methods). Leupeptin, when added, was present in the slice medium throughout the $1 \mathrm{hr}$ preincubation period and the incubation with homocysteate.

alone (Fig. 1A); in fact, since calcium approximately doubled glutamate binding, both in untreated and in glutamate-preincubated membranes, the binding increase in absolute numbers was much larger after glutamate induction. Whether glutamate binding increase induced by TG is based on still another regulatory mechanism remains to be elucidated.

An induction of $\mathrm{Cl}^{-}$-dependent glutamate-binding sites similar to the one described here has recently been reported by Malouf et al. (1984). Neuroblastoma cells exposed to millimolar concentrations of glutamate in the culture medium had $2.5 \times$ more $\mathrm{Cl}^{-}$-dependent glutamate binding sites in their membrane fractions. The pharmacological profile of induction was essentially the same as that reported here. Calcium activation and induction by glutamate were also additive in their system. However, it is somewhat surprising that exposure times of at least $3 \mathrm{~d}$ were necessary to induce a maximal induction, whereas induction in hippocampal slices reaches maximal values within 20-60 min (Table 5). Thus, it remains to be determined whether induction in these two systems is caused by the same mechanism.

\section{Possible mechanisms for glutamate binding induction;} evidence for a low-affinity glutamate binding site

The experiments reported here lead to several interrelated qucstions: (1) What is the mechanism underlying binding site induction? (2) What is the nature of the binding site, which has to be occupied to induce the new, high-affinity glutamate binding sites? And (3) in what form did the induced binding sites exist prior to the induction?

Although the process underlying binding-site induction is not yet understood, the available data lead to certain hypotheses about probable mechanisms. However, we would like, first, to discuss some mechanisms that are most likely not involved in binding-site induction. First, nonspecific effects of glutamate on membranes or membrane proteins can be safely ruled out for several reasons: (1) Many glutamate analogs, such as L-aspartate, $\mathrm{D}$-aspartate, quinolinate, etc., did not induce a binding increase; and D-glutamate, whose physicochemical properties are identical to those of L-glutamate, was much less potent than the latter. (2) Preincubating membranes at $\mathrm{pH}$ values between 6.5 and 8.5 did not elicit a binding increase (data not shown). (3) Large changes in the ionic composition of the incubation media, e.g., addition of $200 \mathrm{~mm}$ morpholinoethane sulfonic acid (MES)/ Tris, $\mathrm{pH} 7.4$, to the standard incubation medium did not lead to an increase in glutamate binding (data not shown).

Incomplete removal of glutamate is again most unlikely to cause a binding increase. Residual glutamate from the preincubation would displace $\left[{ }^{3} \mathrm{H}\right]$ glutamate from the binding sites and thus cause an apparent reduction in binding. Residual glutamate could only elicit a binding increase if binding would be highly cooperative. However, Hill coefficients for $\mathrm{Cl}^{-}$-dependent glutamate binding are approximately 1 (Fig. 2; Monaghan et al., 1983). We have further tested membrane samples from three membrane preparations, preincubated for 40 min with $10 \mathrm{mM}$ glutamate, for residual glutamate, using separation by HPLC. These membrane samples showed a three- to fourfold binding increase over control membranes over a 40 -fold protein concentration range (0.3-12 $\mu \mathrm{g}$ protein/incubation). The amount of $3.3 \pm 0.8(\mathrm{SEM}, n=3) \mathrm{pmol}$ glutamate $/ \mu \mathrm{g}$ protein found in thesc membranes could account for concentrations of 20-700 nM free glutamate in the incubation with $\left[{ }^{3} \mathrm{H}\right.$ lglutamate, depending on the protein concentration chosen for the binding assay. However, the free glutamate concentration probably is much lower, since there is evidence that part of this residual glutamate is trapped in membrane vesicles and thus cannot interfere with $\left[{ }^{3} \mathrm{H}\right]$ glutamate binding. We also preincubated membranes for $20 \mathrm{~min}$ at $35^{\circ} \mathrm{C}$ with $0.5 \mu \mathrm{M}$ unlabeled glutamate prior to adding $\left[{ }^{3} \mathrm{H}\right]$ glutamate to simulate possible effects of residual glutamate, and did not find any stimulation of binding by this pretreatment.

We thus believe that the induction of glutamate binding is based on a specific process that selectively controls the number or the state of the high-affinity $\mathrm{Cl}^{-}$-dependent glutamate binding sites. Obvious candidates for such regulatory functions are the numerous intracellular messenger systems and the phosphorylation/dephosphorylation processes they control. However, various observations suggest that none of those processes is involved in glutamate binding-induction. First, our experiments were done on lysed and sonicated membrane preparations, which could at best contain traces of ATP and messenger compounds. Addition of $\mathrm{Mg}^{2+}$ plus ATP, GTP, or Gpp(NH)p to the mem- 
branes indeed had no effect on either basal binding or bindingsite induction. Receptor dephosphorylation is unlikely, since the phosphatase inhibitor, $\mathrm{F}^{-}$, does not prevent induction. Moreover, the reversible activation and deactivation of binding sites described in Table 4B would require the presence of ATP at least at some point in the cycle, if phosphorylation were involved.

The glutamate concentrations necessary, during the preincubation period, to induce a binding increase are in the millimolar range. This strongly suggests that these membranes possess a low-affinity site for glutamate, distinct from the high-affinity sites detected in the binding assay. Since there are no techniques that would detect binding sites with such low affinities, we must infer the properties of this hypothetical low-affinity site from the induction experiments. One remarkable characteristic is the close resemblance of this site's pharmacological profile with that of the high-affinity $\mathrm{Cl}^{-}$-dependent binding site itself, in spite of the thousand-fold difference in affinities. This suggests that the low- and high-affinity sites might in fact be two interconvertible forms of the same binding site. Prolonged occupation of the low-affinity site by a ligand might trigger a conversion into the high-affinity form that persists for at least hours after removal of the ligand. Short exposure to $\mathrm{Na}^{+}$might convert the highaffinity site back into the low-affinity form. This latter observation might raise doubts about the possible physiological significance of the induction process, since receptors are continuously exposed to $\mathrm{Na}^{+}$in both the intra- and the extracellular compartments. However, it might well be the case that additional factors control the conversion between low- and highaffinity forms of the binding sites, since we find a stable population of high-affinity binding sites in freshly prepared membranes. Thus, the rapid conversion of high-affinity sites back into the low-affinity form might be confined to the in vitro situation.

Since glutamate binding in isolated membranes can be cyclically activated by high glutamate concentrations, deactivated by exposure to $\mathrm{Na}^{+}$, and then reactivated by glutamate (Table 4B), the conversion between low- and high-affinity forms may be caused simply by reversible conformational changes within the binding protein, and thus might not require intracellular regulatory processes.

One further possibility is that the high-affinity and the postulated low-affinity sites are different, but functionally interconnected, binding sites. Transient occupation of the low-affinity site might trigger a long-lasting conversion of the high-affinity binding site from a nonfunctional to a functional state. This hypothesis is supported by the experiments involving TG. Since TG does not interact with the high-affinity site itself, one may assume that a modulatory site is present, in close association with the high-affinity site. It is then conceivable that the site for TG is identical with the low-affinity site for glutamate and glutamate analogs. Such a binding site complex, involving several nonequivalent sites, is, of course, at the moment purely hypothetical; but it is not implausible, given the multiplicity of the binding sites found in the GABA/benzodiazepine/barbiturate receptor complex (Olsen, 1981).

To conclude, the results presented here indicate that $\mathrm{Cl}^{-}$dependent glutamate binding cannot convincingly be interpreted in terms of a simple binding process to a stable population of immutable receptor sites. They suggest, instead, that a lowaffinity site exists in hippocampal membranes which itself can be converted into a high-affinity site upon prolonged occupation, or which is a regulatory site in a multiple binding site complex.

\section{Possible physiological significance of binding-site induction}

The relationship between the $\mathrm{Cl}^{-}$-dependent glutamate binding sites assayed in the present experiments and the synaptic receptors for various hippocampal pathways has been discussed elsewhere (Baudry and Lynch, 1984). Suffice it to say that circumstantial evidence links the two but compelling experiments have yet to be reported. If $\mathrm{Cl}^{-}$-dependent glutamate binding is a valid measure of functional synaptic receptors, then the induction described here might represent a physiologically relevant process, which leads to an increased number of synaptic receptors and to increased synaptic transmission, provided that synaptic strength is limited by receptor number. It thus could have important implications for the understanding of the variety of physiological changes that occur in the hippocampus after intense synaptic stimulation. Here, brief bursts of stimulation can cause an increase in glutamate binding sites as well as potentiation of synaptic potentials (Lynch et al., 1982). During these bursts, enough transmitter might accumulate in the synaptic cleft to temporarily convert some low-affinity protoreceptors into functional receptors. Additional receptors might then be irreversibly activated by intracellular calcium, and structural changes might be induced by the previously described mechanism involving a calcium-sensitive protease (Baudry and Lynch, 1984). The different temporal components in the decay of synaptic potentiation, with half-lives ranging from hours to days (Racine et al., 1983), might thus corrclate with the different activation mechanisms for $\mathrm{Cl}^{-}$-dependent glutamate binding sites.

Repeated subthreshold stimulation can also produce seizures in the hippocampus and, with repetition, the threshold for producing these is substantially reduced (kindling) (Racine and Burnham, 1984). Each seizure is followed by a prolonged depression of physiological activity, a period in which the cells are depolarized. While experimental studies of extracellular amino acid concentrations have not been reported, it is certainly possible that the processes that control synaptic glutamate concentrations are disturbed for considerable periods by the induction of kindling. If so, then the inductive effects reported above might explain the lowered threshold of hippocampal circuitry for seizures, as well as the increased number of binding sites found in the kindled hippocampus.

A transfer of a receptor from a low- to a high-affinity state does not necessarily indicate a greater physiological effect. Upon prolonged exposure to agonists, the nicotinic ACh receptor converts from a low-affinity state, which is the physiologically active form of the receptor, to a high-affinity state, in which the bound agonist no longer elicits opening of the ion-channel (Prinz and Maelicke, 1983; Rang and Ritter, 1970). This state of the receptor has been termed "desensitized." By analogy, the induction of binding sites after exposure to high glutamate concentrations might be interpreted as a "desensitization" process.

According to this alternative interpretation, the postulated low-affinity sites would be the actual, functional synaptic receptors, whereas the high-affinity sites revealed in the binding assay would represent a pool of desensitized receptors that do not respond to the binding of glutamate with channel-opening. The binding sites normally found in freshly prepared membranes might represent a small pool of desensitized receptors already present in the tissue, where they might be in dynamic equilibrium with the functional receptors. Receptor sites with millimolar affinities may at first seem unrealistic in view of the fact that most receptor systems studied have dissociation constants in the nanomolar concentration range. However, it should be borne in mind that the fast-switching synaptic receptors must have association and dissociation times for their natural ligands in the millisecond time scale, and that low-affinity sites are more likely to meet these demands. The slow association and dissociation rates of the $\mathrm{Cl}^{-}$-dependent high-affinity glutamate binding site are in fact incompatible with the kinetics of a fastswitching synaptic receptor, and suggest that the receptor would have to undergo some kind of conversion into the high-affinity form identified in the binding assay. (However, mechanisms 
other than the induction described here might cause this conversion into the slowly dissociating form, e.g., removal of $\mathrm{Na}^{+}$ during the membrane preparation.)

Desensitization is of unclear functional significance and conditions leading to desensitization may be different for each receptor type. Even if glutamate binding induction should represent receptor desensitization, any analogy with the ACh receptor should be made with caution. The conversion between the low- and high-affinity states would indeed be orders of magnitude slower in the case of the glutamate receptor, thus "freezing" receptors for hours in the desensitized state after removal of the ligand. One other important difference would be that glutamate receptor desensitization could be induced by both agonists and antagonists, whereas desensitization is restricted to agonists in the case of the ACh receptor.

The question of whether induction of new binding sites is accompanied by a change in synaptic strength and, if so, whether this reflects a reduction (as predicted from the "desensitization" interpretation) or a potentiation of synaptic responses must await future physiological experiments. The major difficulty faced by studies of this type is that the opening of channels throughout the entire neuron for extended periods can be expected to be deleterious to the cell, and indeed, amino acids do produce excitotoxic effects (Zaczek and Coyle, 1982). This does not rule out a physiological role for high-transmitter concentrations in regulating receptors since, under physiological circumstances, only a small fraction of the total synaptic population would be activated by the activity in a given afferent. Under these conditions, local potentiation could occur without disrupting the ionic and metabolic homeostasis throughout the target neuron. One possible way to alter the number of receptors by prolonged cxposure to amino acids without producing cxcitotoxic effects would be to use antagonists of the synaptic receptor. Compounds such as APB and D-aminoadipate have only weak agonist properties but strong affinities for the $\mathrm{Cl}^{-}$-dependent site and, as described above, are powerful inducers of high-affinity sites. Accordingly, it should be possible to apply these compounds in high concentrations for extended periods, wash the slices clean, and test for changes in excitatory synaptic potentials.

\section{References}

Baudry, M., and G. Lynch (1980) Regulation of hippocampal glutamate receptors: Evidence for the involvement of a calcium-activated protease. Proc. Natl. Acad. Sci. USA 77: 2298-2302.

Baudry, M., and G. Lynch (1984) Glutamate receptor regulation and the substrates of memory. In Neurobiology of Learning and Memory, G. Lynch, J. L. McGaugh, and N. M. Weinberger, eds., pp. 431-447, Guilford, New York.

Baudry, M., M. Bundman, E. Smith, and G. Lynch (1981a) Micromolar calcium stimulates proteolysis and glutamate binding in rat brain synaptic membranes. Science 212: 937-938.

Baudry, M., S. Halpain, D. Arst, E. Smith, and G. Lynch (1981b) Physiological regulation of glutamate receptor binding. Soc. Neurosci. Abstr. 7: 445.

Baudry, M., K. Kramcr, and G. Lynch (1983) Irreversibility and time course of calcium stimulated $\left[{ }^{3} \mathrm{H}\right]$ glutamate binding to rat hippocampal membranes. Brain Res. 270: 142-145.

Bradford, M. (1976) A rapid and sensitive method for the quantification of microgram quantities of protein utilizing the principle of protein-dye binding. Anal. Biochem. 72: 248-254.

Fagg, G. E., A. C. Foster, E. E. Mena, and C. W. Cotman (1982) Chloride and calcium ions reveal a pharmacologically distinct population of L-glutamate binding sites in synaptic membranes: Corre- spondences between biochemical and electrophysiological data. J. Neurosci. 2: 958-965.

Fagg, G. E., A. C. Foster, E. E. Mena, and C. W. Cotman (1983) Chloride and calcium ions separate L-glutamate receptor populations in synaptic membranes. Eur. J. Pharmacol. 88: 105-110.

Ferkany, J., R. Zaczek, A. Markl, and J. T. Coyle (1983) Phenylalanine-L-glutamate enhances specific $\left[{ }^{3} \mathrm{H}\right]$-2-amino-7-phosphono heptanoic acid and $\left[{ }^{3} \mathrm{H}\right]$-L-glutamate binding and inhibits specific $\left[{ }^{3} \mathrm{H}\right]-$ kainic acid binding to rat brain membranes in vitro. Soc. Neurosci. Abstr. 9: 262.

Ferkany, J., R. Zaczek, A. Markl, and J. T. Coyle (1984) Glutamatecontaining dipeptides enhance specific binding at glutamate receptors and inhibit specific binding at kainate receptors in rat brain. Neurosci. Lett. 44: 281-286.

Foster, A. C., and G. E. Fagg (1984) Acidic amino acid binding sites in mammalian neuronal membranes: Their characteristics and relationship to synaptic receptors. Brain Res. Rev. 7: 103-164.

Lee, K., M. Oliver, F. Schottler, and G. Lynch (1981) Electron microscopic studies of brain slices: The effect of high frequency stimulation on dendritic ultrastructure. In Electrical Activity in Isolated Mammalian CNS Preparations, G. Kerkut and H. V. Wheal, eds., pp. 189-212, Academic, New York.

Lindroth, P., and K. Mopper (1979) High performance liquid chromatographic determination of subpicomole amounts of amino acids by precolumn fluorescence derivatization with o-phthaldialdehyde. Anal. Chem. 51: 1667-1674.

Lynch, G., S. Halpain, and M. Baudry (1982) Effects of high frequency synaptic stimulation on glutamate binding studied with a modified in vitro hippocampal slice preparation. Brain Res. 244: 101-111.

Malouf, A. T., J. T. Coyle, and R. L. Schnaar (1984) Agonists and cations regulate the glutamic acid receptors on intact neuroblastoma hybrid cells. J. Biol. Chem. 259: 12,763-12,768.

Mamounas, L., R. F. Thompson, G. Lynch, and M. Baudry (1984) Classical conditioning of rabbit eyelid responses increases glutamate receptor binding in hippocampal synaptic membranes. Proc. Natl. Acad. Sci. USA 81: 2548-2552.

Mena, E. E., G. E. Fagg, and C. W. Cotman (1982) Chloride ions enhance L-glutamate binding to rat brain synaptic membranes. Brain Res. 243: 378-381.

Monaghan, D. T., M. C. McMills, A. R. Chamberlain, and C. W. Cotman (1983) Synthesis of $\left[{ }^{3} \mathrm{H}\right] 2$-amino-4-phosphonobutyric acid and characterization of its binding to rat brain membranes: A selective ligand for the chloride/calcium dependent class of L-glutamate binding sites. Brain Res. 278: 137-144.

Olsen, R. W. (1981) GABA-benzodiazepine-barbiturate receptor interactions. J. Neurochem. 37: 1-13.

Prinz, H., and A. Maelicke (1983) Interaction of cholinergic ligands with the purified acetylcholine receptor protein. J. Biol. Chem. 258: $10,273-10,282$.

Racine, R. J., and W. M. Burnham (1984) The kindling model. In Electrophysiology of Epilepsy, P. A. Schwartzkroin and H. V. Wheal, eds., pp. 153-171, Academic, London.

Racine, R. J., N. W. Milgram, and S. Hafner (1983) Long-term potentiation phenomena in the rat limbic forebrain. Brain Res. 260: 217-231.

Rang, H. P., and J. M. Ritter (1970) On the mechanism of desensitization at cholinergic receptors. Mol. Pharmacol. 6: 357-382.

Savage, D. D., L. L. Werling, J. V. Nadler, and J. O. McNamara (1982) Selective increase in $\mathrm{L}-[3 \mathrm{H}]$ glutamate binding to a quisqualate-sensitive site on hippocampal synaptic membranes after angular bundle kindling. Eur. J. Pharmacol. 85: 255-256.

Werling, L. L., K. A. Doman, and J. V. Nadler (1983) L- $\left[{ }^{3} \mathrm{H}\right]$ Glutamate binding to hippocampal synaptic membranes: Two binding sites discriminated by their differing affinities for quisqualate. J. Neurochem. 41: 586-593.

Zaczek, R., and J. T. Coyle (1982) Excitatory amino acid analogues: Neurotoxicity and seizures. Neuropharmacology $21: 15-26$. 